\title{
Progress of Research in Neonatal Sepsis
}

\author{
Sheng Chen and Yuan Shi
}

\begin{abstract}
Neonatal sepsis remains a significant global problem with little progress made despite major efforts. At present, there is a lack of an accepted international consensus on the definition, diagnosis, and treatment of neonatal sepsis; the unclear understanding of the pathogenesis of neonatal sepsis leads to blindness in treatment, which will result in an unsatisfactory therapeutic outcome. In addition, some serious diseases caused by noninfectious factors, such as trauma, stress, asphyxia, and so on, have very similar pathophysiological results with neonatal sepsis. In this review we synthesize the recent advances in definition, incidence, causative agents, risk factors, pathophysiology, clinical manifestations, and diagnosis and treatment of neonatal sepsis. Of course, there are still many challenges to neonatal sepsis in many ways.
\end{abstract}

\section{Keywords}

Pediatric $\cdot$ Neonate $\cdot$ Sepsis $\cdot$ Septic shock $\cdot$ Definition $\cdot$ Surviving sepsis campaign Antibiotics $\cdot$ Burden $\cdot$ Causative agent $\cdot$ Risk factor $\cdot$ Diagnosis $\cdot$ Management

\subsection{Introduction}

Neonatal sepsis remains the third leading cause of neonatal death and is one of the leading causes of death among children under 5 years of age, especially in developing countries, which has become a public health problem. The clinical

\footnotetext{
S. Chen

Department of Pediatrics, Southwest Hospital, Third Military Medical University, Chongqing, China

Y. Shi (四)

Children's Hospital, Chongqing Medical University, Chongqing, China

Daping Hospital, Army Medical University, Rawalpindi, Pakistan

(C) Springer Nature Singapore Pte Ltd. 2019

X. Fu, L. Liu (eds.), Severe Trauma and Sepsis, https://doi.org/10.1007/978-981-13-3353-8_16
} 
manifestations of neonatal sepsis range from subclinical infection to severe focal or systemic diseases. Pathogens can come from intrauterine infections, infections of maternal flora, or hospital- or community-acquired infections. Preterm infants are immunologically immature. During the period of hospitalization, more invasive procedures during hospitalization increase the chances of bacterial infection. However, in many cases, serious diseases caused nonpathogenic bacteria, such as trauma, stress, asphyxia, hypoxia, and so on, have similar pathophysiological processes with neonatal sepsis, which is also worthy of our study. In this review, we discussed the most common problems and challenges in the definition, burden, etiology, risk factors, pathophysiology, diagnosis, and treatment of neonatal sepsis, with a focus on developing countries.

\subsection{Definition of Neonatal Sepsis}

Since the American College of chest Physicians/Society of critical Care Medicine (ACCP/SCCM) proposed the concept of sepsis in 1991, experimental and clinical studies on sepsis have been in the ascendant. The first edition of sepsis in 1991 was defined as systemic inflammatory response syndrome (SIRS) caused by infection. The SIRS is identified by two or more symptoms including fever or hypothermia, tachycardia, tachypnea, and change in blood leucocyte count; the sepsis-1 emphasizes that the direct factor leading to body damage is immune response rather than pathogens. In December 2001, an international conference on sepsis was held in Washington, USA. The definition and diagnostic criteria of sepsis proposed by ACCP/SCCM in 1991 were discussed and re-evaluated. The meeting concluded that the previous criteria for the diagnosis of sepsis were too loose, with a high sensitivity and low specificity, which may lead to overdiagnosis of sepsis. As a result, the second definition of sepsis (sepsis-2) has been revised, and more stringent diagnostic criteria have been introduced than in the past. However, the clinical application of modified sepsis is limited due to the complexity of the diagnostic criteria. Both the "Sepsis syndrome" proposed by Bone and the definition of sepsis proposed at the ACCP/SCCM meeting in 1991 are all aimed at adults, such as the heart rate and respiratory rate in SIRS are the standard of adults, so these concepts have not been applied to children. In 2016, a sepsis task force was established and re-evaluated the definition of sepsis. According to the newest definitions (sepsis-3), sepsis should be defined as life-threatening organ dysfunction caused by a dysregulated host response to infection. Septic shock should be defined as a subset of sepsis in which particularly profound circulatory, cellular, and metabolic abnormalities are associated with a greater risk of mortality than with sepsis alone [1]. Unfortunately, to this day, there is no precise definition of neonatal sepsis. But according to the latest definition, neonatal sepsis also contains three characteristics, the first of which emphasizes infection; neonatal sepsis can be caused by bacteria, viruses, or fungi (yeast); however, many neonatal sepsis is not entirely caused by infection; some noninfectious factors such as asphyxia, trauma, and stress can also be associated with clinical sepsis. The second characteristic is the dysregulated host response, which is a key factor leading to hemodynamic changes and other organ damage. The third characteristic is a 
life-threatening organ dysfunction, which emphasizes the consequences of sepsis. Among these three characteristics, we should pay more attention to host's own immune disorder, because it is the central link of neonatal sepsis, but also the key to prevention and control. According to the age of onset and timing of the sepsis episode, it can be divided into two types: early-onset sepsis (EOS) and late-onset sepsis (LOS). The clinical manifestations of EOS usually occur in the first $72 \mathrm{~h}$ of life, most of the symptoms occur within $24 \mathrm{~h}$ of birth. Some clinicians define EOS, especially those caused by group B Streptococcus (GBS), as infections that occur less than 7 days of age. EOS is acquired before or during childbirth and is usually transmitted vertically from mother to child. Pathogens enter the fetus through the respiratory tract (fetal respiration), gastrointestinal tract (swallowing), skin, ears, etc. LOS refers to sepsis presenting after $72 \mathrm{~h}$ of life, and pathogens invade newborns through medical personnel, family members, contaminated equipment, etc.

\subsection{Burden of Neonatal Sepsis}

In 2010 worldwide, 7.6 million children less than 5 years old died, predominantly due to infectious causes including sepsis; neonatal deaths accounted for $40 \%$ of the total lives lost [1]. In 1990, both the United Nations (UN) and World Health Organization (WHO) prioritized a second/third reduction in the unacceptable child mortality rate by 2015 . However, in $2013,44 \%$ of deaths in children under the age of 5 occurred during the neonatal period, up from 37\% in 1990. Despite major advances in neonatal care and increasing research, in developed countries, four of every ten infants with sepsis die or experience major disability including significant permanent neurodevelopmental impairment [2]. Prematurely born neonates experience the highest incidence and mortality of sepsis among all age groups $[3,4]$. In the United States, a staggering 36\% of neonates born before 28 weeks completed gestation suffer at least one episode of bloodstream infection (BSI) during their birth hospitalization with up to a 50\% associated mortality [5]. Compared to term infants, sepsis in preterm infants is up to 1000-fold more common and is associated with higher rates of mortality and lifelong neurodevelopmental handicaps $[6,7]$. Of note, it is estimated that $11 \%$ of the 135 million births globally occur before 37 weeks of gestation, and preterm births have been increasing steadily, especially in developed countries [8]. In 2005, there were 41,353 newborns from 80 hospitals in China, with 2060 cases of sepsis. The incidence of sepsis was about $5 \%$.

\subsection{Pathogens of Neonatal Sepsis}

\subsubsection{EOS}

Intrauterine infection is a serious complication of pregnancy, which can lead to stillbirth and premature delivery and significantly increase the morbidity and mortality of neonatal sepsis and brain injury. Under normal circumstances, the amniotic cavity is usually sterile. There are a large number of aerobic and anaerobic bacteria 
in the human birth canal, which can lead to infection of newborn before or during delivery under different pathological conditions, the most common pathway is the ascending invasion of microbes from the lower reproductive tract. Romero et al. ascending intrauterine infection is divided into four phases. Stage I: Disorder of vaginal and/or cervical microbiota or presence of pathogenic microorganisms in the cervix canal. Bacterial vaginosis may be an early manifestation of this period. Stage II: Microorganisms enter the uterine cavity and colonize in the decidual tissue and then cause inflammation, which in turn develops into chorioamnionitis. Stage III: Microorganisms continue to invade and colonize in the chorion and amniotic membrane. Later, the pathogens may invade the fetal blood circulation and lead to chorioangiitis and/or umbilical phlebitis; pathogens can also cross amniotic membranes into the amniotic cavity. Stage IV: The fetus is infected by direct contact or inhalation, leading to otitis, conjunctivitis, umbilical inflammation, congenital pneumonia, etc. Chorioamnionitis is an inflammatory reaction of the chorion, and neutrophils infiltration is the main pathological feature. Chorioamnionitis is divided into two types: acute chorioamnionitis (ACAM) with clinical symptoms including fever, maternal or fetal tachycardia, uterine tenderness, and amniotic fluid odor and histologic chorioamnionitis (HCAM) without clinical symptoms. The latter was only found in microscopic examination of placental pathology. The incidence of the latter was two to three times higher than that of ACAM. In addition, newborns may be infected when exposed to potentially pathogenic bacteria, viruses, or fungi through the birth canal. The incidence of histological chorioamnionitis is negatively correlated with gestational age and was directly related to duration of membrane rupture $[3,4]$. Whether asymptomatic neonates with gestational age $\geq 35$ weeks should be treated with empirical antibiotics due to maternal chorioamnionitis is still controversial. A recent study showed that the use of antibiotics in asymptomatic newborns exposed to chorioamnionitis should be evaluated comprehensively on the basis of maternal risk factors and neonatal clinical examinations; with maternal body temperature as a continuous variable for risk factors, the clinical examination of newborn mainly includes blood culture, blood cell count, and hsCRP. Simple observation without laboratory tests may miss some asymptomatic children.

\subsubsection{LOS}

The neonatal immune system is not mature enough and the function is not perfect; the innate immune system, including phagocytes, antigen-presenting cells, and natural killer cells, and the complement system provide a defense against pathogens. Decreased function of neutrophils and low concentrations of immunoglobulins increase the susceptibility of preterm infants to invasive infection. As infants age, they are exposed to environmental organisms that might be pathogenic. Contact with family members, hospital personnel, contaminated equipment, and nutritional sources all increase the probability of disease exposure. Twenty to $40 \%$ of nosocomial infections are related to doctors' hand contamination. Despite this importance, hand hygiene has not received sufficient attention. Other risk factors for LOS 
include intravascular catheterization, delayed enteral nutrition, prolonged parenteral nutrition, prolonged mechanical ventilation, surgery, etc. Most cases of meningitis are late-onset infections resulting from hematogenous spread via the choroid plexus into the CNS; less often, late-onset meningitis results from contiguous spread as a result of contamination of open neural tube defects, ventricular devices, congenital sinus tracts, or penetrating wounds from fetal scalp monitors. Subdural effusion, ventriculitis, hydrocephalus, abscess formation, and septic infarcts are main complications of neonatal meningitis.

\subsubsection{Causes of Neonatal Sepsis}

The causative agent of neonatal sepsis may be bacteria, viruses, or fungi microorganisms. The most common pathogens causing EOS are Streptococcus agalactiae (GBS) and Escherichia coli. Of the nearly 400,000 live births from 2006 to 2009 at the academic Neonatal Center in the United States, 389 newborns had early-onset infections (0.98 infections per 1000 live births), of which 43\% were GBS (0.41 per 1000 live births) and $29 \%$ were $E$. coli ( 0.28 per 1000 livebirths). Most of the newborns infected with GBS were term infants, while those infected with $E$. coli were more common in premature infants. The infection rate was negatively correlated with birth weight: $54 \%$ at 22-24 weeks, $30 \%$ at 25-28 weeks, $12 \%$ at 29-33 weeks, and 3\% at more than 37 weeks' gestation. The mortality rates of newborns infected with GBS and Escherichia coli were 9\% and 33\%, respectively. In Europe or North America, GBS used to be the most common pathogen of premature infections, but at present $E$. coli almost replaced GBS as the most important pathogen associated with early-onset infection in preterm infants and very low birth weight infants $[3,9,10]$. However, in China, GBS infection is not as serious as that in Europe and America; the most common pathogens include coagulase-negative staphylococci (69.2\%) and Escherichia coli (15.5\%). Except for GBS and Escherichia coli, some unusual pathogens such as Listeria monocytogenes, non-typeable Haemophilus influenzae, Gram-negative enteric bacilli, and Candida spp. can also be pathogenic bacteria of EOS $[11,12]$. In China LOS can also be associated with E. coli, Klebsiella pneumoniae, Acinetobacter baumannii, Staphylococcus aureus, Pseudomonas aeruginosa and fungal. However, L. monocytogenes is very rare. In neonatal intensive care units, Coagulase negative staphylococci are also the most common pathogens of LOS. Coagulase-negative staphylococci and Staphylococcus aureus are most commonly in neonates with vascular access catheters. For example, of the 117 infants with Staphylococcus aureus septicemia in 13 neonatal units in the United Kingdom, 8 (7\%) were caused by methicillin-resistant $S$. aureus (MRSA). The mean gestational age and birth weight were 27 weeks and $850 \mathrm{~g}$, respectively. The incidence of Staphylococcus aureus sepsis in live births and infants less than $1500 \mathrm{~g}$ was 0.6 per 1000 and 23 per 1000, respectively. Ninety-four of the cases were late-onset infection, which occurred more than $48 \mathrm{~h}$; all of the seven episodes categorized as early-onset were MRSA infection. Half of the infants showed non-localizing signs of sepsis, and half of the infants had central venous access when they were infected with Staphylococcus aureus [13]. Other rare 
pathogens of early and late sepsis are Streptococcus pyogenes, Enterococcus faecalis, and Neisseria gonorrhoeae. Additionally, Neisseria meningitidis, Mycoplasma hominis, and Ureaplasma spp. have been associated with early-onset sepsis, pneumonia, meningitis, cerebral abscesses, and osteomyelitis. The prevalence of pathogens varies greatly from region to region, and Gram-negative bacteria are a significant burden in resource-poor areas [14]. Viruses can also cause neonatal sepsis, most commonly herpes simplex virus (HSV) and enterovirus, both of which are more associated with late-onset sepsis. Neonatal HSV infection has a high incidence and mortality, which may be located in the eyes and mouth, skin, involve the central nervous system, or spread to the liver, lungs, and adrenal glands. The onset time was 5-9 days. Neonatal HSV infection can be caused by HSV-1 or HSV-2; HSV-1 will become more common with the increase of HSV-1 genital infection $[15,16]$. Neonates with enterovirus infections might develop myocarditis, meningoencephalitis, and hepatitis, following fever, lethargy, poor feeding, irritability, jaundice, and hypoperfusion. Infants younger than 10 days of age who are exposed to echoviruses, coxsackie group B viruses, and parechoviruses through maternal shedding are not normally able to benefit from transplacental transfer of maternal antibodies because of their inability to produce an immune response and because of the timing of recent maternal infections [17]. Fungi, particularly yeasts, are associated with a growing number of systemic infections, usually acquired during prolonged hospitalization of premature infants. Candida spp. are the third most common cause of late-onset neonatal sepsis in low birth weight infants $(<1500 \mathrm{~g})$, and Candida parapsilosis is a main pathogen in neonates with central venous access. The incidence of $C$. parapsilosis infection is relatively low in Europe compared with North America and Australia [18]. Preterm infants, especially very low birth weight infants, have low immune function, which is the main risk group of neonatal fungal infection. Other risk factors included prolonged intensive care, parenteral nutrition, mechanical ventilation, central venous catheterization, prolonged use of broad-spectrum antibiotics and $\mathrm{H} 2$ receptor blockers, and postpartum corticosteroids. In a prospective observational cohort of 1515 infants with $1000 \mathrm{~g}$ birthweight or less who were from 19 academic medical centers in the United States, invasive candidiasis occurred in 137 (9\%). Potentially modifiable risk factors included receipt of broad-spectrum and antenatal antibiotics including third-generation cephalosporins, central venous catheters, receipt of intravenous lipid emulsion, antacid medications, postnatal corticosteroids, and the presence of an endotracheal tube [19].

\subsection{Risk Factors}

\subsubsection{EOS}

\subsubsection{Maternal Factors}

Premature birth ( $<37$ weeks), prolonged time $(>18 \mathrm{~h})$ of membranes rupture, maternal peripartum infection, and low socioeconomic status are closely related to EOS. A study [20] differentiated the categories of predisposing factors into the following: maternal colonization, risk factors for infection, and maternal infection. 
Maternal colonization was determined that the reproductive tract/genital bacterial cultures were positive no matter whether the pregnant women had clinical signs or symptoms or not. Maternal risk factors included prelabor rupture of membranes during the term of the fetus, preterm prelabor rupture of membranes, and duration of rupture of membranes longer than 8-24 h or undefined. They defined maternal infection according to the following criteria: clinical signs of infection [uterine tenderness, intrapartum maternal fever, maternal tachycardia, malodorous vaginal discharge, elevated C-reactive protein (CRP), elevated white cell count, physician diagnosis of clinical chorioamnionitis] or the presence of laboratory confirmed bacterial infection [bacteremia, urinary tract infections, amnionitis, or chorioamnionitis; documented by positive polymerase chain reaction (PCR) at the level of the amniotic fluid only; positive cultures of biologic fluids; or histopathologically confirmed chorioamnionitis], and the multivariate logistic regression analysis of a Chinese 1:4 case-control study [21] involving 147 EOS newborns and 588 controls showed that cesarean section (OR $0.103,95 \% \mathrm{CI}, 0.041-0.258$ ), maternal age $>35$ years [odd ratio (OR) 4.835, 95\% confidence interval (CI), 1.170-19.981], and premature rupture of membranes (OR 0.207, 95\%CI, 0.078-0.547) represent the major predisposing factors to neonatal sepsis. Furthermore, in the univariate analysis, urban residence (OR 5.079, 95\% CI, 2.899-8.990), fixed occupation of mothers (OR 0.439, 95\% CI, 0.289-0.668), abnormal fetal position (OR 1.621, 95\% CI, $1.340-1.962$ ), parity (OR $1.859,95 \% \mathrm{CI}, 1.188-2.908$ ), fetal times (OR 1.212, 95\%CI, 1.041-1.412), amniotic fluid volume abnormalities (OR 0.200, 95\%CI, 0.054-0.745), placental abnormalities (OR 0.050, 95\% CI, 0.006-0.428) pregnancyinduced hypertension (OR $0.297,95 \% \mathrm{CI}, 0.122-0.726$ ), and pregnancy-induced hypertension (OR $0.297,95 \% \mathrm{CI}, 0.122-0.726$ ) seemed to predispose to neonatal infection; unfortunately these results were not confirmed by multivariate regression analysis evaluation. The role of young maternal age ( $<20$ years old) has been questioned, although it was previously thought to be an important predisposing factor of neonatal sepsis, possibly related to the high colonization rate of GBS in the maternal vagina [22]. Epidemiological studies have shown an increase in the incidence of EOS among black newborns compared with white newborns, although this explanation seems to be better related to the different socioeconomic conditions of the two races [23]. Certain obstetric practices such as membrane-stripping, invasive fetal monitoring, and intrapartum vaginal exams may be important causes of early neonatal infection [24].

\subsubsection{Neonatal Factors}

Among neonatal factors able to promote EOS, the alterations of the innate immune response can play a significant role. As the adaptive response requires 5-7 days from delivery to develop, during this period infants are largely dependent on innate immune system (respiratory and intestinal) barriers and the skin, local immune sentinel cells, [macrophages, endothelium, epithelium, polymorphonuclear cells (PMN), and dendritic cells], antigen presenting immune cells (monocytes, macrophages, and dendritic cells), host defense proteins and peptides (complements, cytokines, chemokines, active phase, and coagulation proteins), as well as 
passively acquired immunoglobulin from the mother. The alterations of the innate immune can play an important role in neonatal EOS. Because the infant's adaptive response will take 5-7 days to form, during that time, infants mainly rely on innate immune system (intestinal and respiratory) barrier and the skin, local immune sentinel cells [polymorphonuclear cells (PMN), macrophages epithelial cells, dendritic cells, and endothelial cells], antigen immune cells (macrophages, monocytes, and dendritic cells), host defense proteins and peptides (cytokines, complements, active and clotting proteins, chemokines), and immunoglobulins acquired passively by the mother. Deficiencies in immunomodulatory genes (mainly X-linked genes) and premature infants (especially low birth weight) are to be closely related to innate immaturity and/or function of the immune system, thus increasing the likelihood of infections [25]. Birth weight is also a risk factor for EOS; premature infants, especially VLBW, are ten times more likely than those born at term, with an overall mortality rate of about one-third [26]. In addition, prematurity (OR $0.059,95 \% \mathrm{CI}, 0.010-0.329)$ and newborn jaundice (OR 0.092, 95\%CI, 0.021$0.404)$ were also sensitive to EOS in a multivariate analysis of a recent case-control study [21]. Other neonatal risk factors include neonatal Apgar scoring at 1 and at 5 min, male sex, wet lung, anemia, fetal distress, hypothermia, intraventricular hemorrhage, and metabolic disorders [20].

\subsubsection{LOS}

A review of studies from the NICHD Neonatal Research Network showed that the likelihood of developing LOS was inversely proportional to birth weight and gestational age [401-750 g (43\%) and highest in infants <25 weeks gestation (46\%)] [27]. Moreover, while maternal intake of corticosteroids was closely related to a significant reduction in EOS (unadjusted OR 0.52; 95\%CI, 0.31-0.88), it was also related to an increased risk of LOS (unadjusted OR 1.29; 95\% CI, 1.10-1.51). However, the increased incidence of LOS in newborns having undergone antenatal administration of corticosteroids must be balanced with the significant reduction in respiratory distress syndrome, bronchopulmonary dysplasia, intraventricular hemorrhage, death rates, and risk of EOS observed after corticosteroids use [27]. A Swedish retrospective case-control study demonstrated that the risk of LOS was directly related to ventilatory treatment and duration of central/umbilical catheters (OR 1.6 and OR 2.6, respectively). Premature rupture of membranes, fever during delivery, and days of continuous positive airway pressure treatment seem to not be relevant to LOS ( $p=$ not significant) [28]. A study of 164 Taiwanese infants with bloodstream infection showed that intraventricular hemorrhage (OR 2.68, 95\% CI, 1.20-5.99; $P=0.017$ ) and parenteral nutrition (OR 6.07, 95\% CI, 1.14-32.32; $P=0.034$ ) were independently associated with blood flow infection. In addition, a retrospective cohort study of NICUS patients using peripherally inserted central catheters from 2003 to 2010 showed that catheter removal due to adverse events was significantly associated with LOS and the use of antibiotics before extubation was not associated with a decrease in the incidence of sepsis [29]. 


\subsection{Pathophysiology of Neonatal Sepsis}

\subsubsection{Host's Own Immune Damage}

Sepsis is mainly caused by host's own uncontrolled inflammation. This means that infections cause damage not only because of the virulence of the pathogen but also because of the host's reaction. When bacteria, fungi, viruses, and bacterial toxins penetrate into the body, they will eventually be discovered by the innate immune system. Innate immunity is the ensemble of cellular and humoral mechanisms that does not need training (i.e., previous exposure to a germ) and that will act quasiautomatically against an insult and generate inflammation in a nonspecific manner $[30,31]$. And when the immune inflammatory response is out of control, the release of inflammatory cytokines will induce the production and release of new cytokines; it causes "cytokine storm" and "cytokine waterfall," which can result in cell and organ damage. The cytokines are a broad category of relatively small proteins $(<40 \mathrm{kDa})$. They cover autocrine, paracrine, and endocrine activities and play an important immunomodulating function. The cytokines can be divided into several categories: chemokines, interleukins, interferons, tumor necrosis factor, and growth factors. The cytokines induced by infection is the result of an autoamplifying phenomenon aiming to destroy the invader and restore the balance of immune system, meanwhile the cytokines can activate neuroendocrine reflex and plasma protein cascade systems such as coagulation, fibrinolysis, and complement systems. Eventually, when a threshold is crossed, a severe clinical syndrome, "sepsis," can occur.

\subsubsection{Microcirculation Dysfunction}

Microcirculation consists of vessels less than $100 \mu \mathrm{m}$ in diameter where oxygen release to the tissues takes place and consists of arterioles, capillaries, and venules. The main cell types comprising the microcirculation are the endothelial cells, smooth muscle cells (mostly in arterioles), leukocytes, red blood cells, and plasma components in blood. Normal function of microcirculation is the main prerequisite for adequate tissue oxygenation and thus organ function. Its function is to transport oxygen and nutrients to tissue cells, ensure adequate immune function, and, in disease, deliver therapeutic drugs to target cells. Although microcirculatory changes in sepsis have been recognized from long ago, clinical interest in this field has grown over the last decade with the development of bedside video microscopic techniques, which confirms that similar microcirculatory disorders can be observed in septic patients. The existence and persistence of this abnormality are related to the prognosis. A study [32] reported that compared with healthy volunteers, sepsis patients had significantly lower vascular density and the proportion of small perfusion vessels, with microcirculatory disturbance more severe in non-survivors; similar results were later confirmed by TreCeik et al. [33]. In addition, Trzeciak also found that the changes of microcirculation were closely related to the severity of organ failure. Sakr et al. [34] has characterized the relationship between the time course of 
microcirculation changes and prognosis in patients with septic shock. Although similar at baseline, the microcirculation of survivors improves rapidly compared with non-survivors, although there was no difference in global hemodynamic variables. More than that, capillary perfusion when shock resolved was closely related to the severity of organ failure. However, the reported statistical association between microcirculatory abnormalities and outcome does not predicate a mechanistic relation. Microcirculatory alterations during sepsis may involve many mechanisms and are related to all the components of the microcirculation [35, 36]: redistribution of blood flow from compliant vascular beds (the splanchnic area and skin) to more important body areas (heart, brain), with secondary microvascular derecruitment; endothelial activation and injury; loss of the glycocalyx, which covers the endothelium and forms an important barrier and transduction system; increased microvascular permeability with capillary leakage, edema formation, and hypovolemia; production of reactive oxygen species (ROS); increased leukocyte adhesion to the endothelial surface; decreased RBC deformability, with secondary capillary plugging that directly damages microcirculatory structures, cellular interactions, and hemostasis; damaged arteriolar smooth muscle cell tone and reactivity, secondary to dysregulation of NO production; and capillary obstruction by platelet/fibrin clots secondary to disseminated intravascular coagulation. The role of endothelial dysfunction, and the consequent increase in leukocyte and platelet adhesion, has recently been considered as a potential mechanism contributing to microcirculatory flow abnormalities [37]. Increased expression of adhesion molecules on endothelial cells and immune cells has been demonstrated during sepsis.

\subsubsection{Mitochondrial Dysfunction}

Mitochondrial is a two-layer membrane coated organelle in most cells. It is the energy-producing structure of the cell and is the main place for cells to breathe oxygen, known as "power house." Oxidative phosphorylation of mitochondria provides more than $90 \%$ of oxygen consumption and ATP for the whole body. The inactivation of pyruvate dehydrogenase, the reversible inhibition of cytochrome by NO, and the inhibition of mitochondrial respiratory enzyme complex by peroxynitrite are the main factors of cell dysfunction and anoxia. Obviously, in severe systemic inflammatory states, especially sepsis, cellular metabolic changes and organ dysfunction are not only common but predict long-term morbidity and mortality. Clearly, mitochondria is not only the target of intracellular injury but also the reaction site of the body to exogenous stress, which has been the focus of basic science and clinical research. However, mitochondria have many metabolic and signaling functions which may play a central role in sepsis expression and final outcome. Along with bioenergetics, mitochondria participate in several important functions, including calcium flux, program cell death pathway, and redox signaling $[38,39]$. The exact reason for mitochondrial dysfunction during sepsis is still unclear. However, inflammatory molecules such as carbon monoxide, nitric oxide (NO), and reactive oxygen/nitrogen species directly damage several components 
of the mitochondrial ETC complexes and mitochondrial respiration [40, 41]. Furthermore, lower metabolic rates in sepsis have been related to decreased expression of major components of electron transfer chain (ETC) complexes and the amounts of mitochondrial DNA [42]. This is an important issue because mitochondrial DNA code nearly $80 \%$ of mitochondrial protein. Besides decreased amounts of ATP synthase and major components in mitochondrial respiratory chain complexes, recent studies have shown that pyruvate dehydrogenase expression was diminished in sepsis and ARDS [43, 44]. It is important to note that preexisting factors contribute to the severity of sepsis, including environmental exposure to toxins, cigarette smoking, metabolic syndrome of obesity and aging, and diabetes [45, 46]. A clinical analysis of sepsis has shown that the extent of mitochondrial impairment in lungs was significantly correlated with mortality rate. In particular, sepsis-associated mortality is significant in patients that develop acute respiratory distress syndrome (ARDS) [47, 48]. Patients who died from severe sepsis had decreased muscle ATP content, while higher levels of ATP were seen in survivors [49]. Patients who died from severe sepsis had lower levels of muscle ATP, while higher levels of ATP were detected in survivors. Organ dysfunction and clinical illness are associated with decreases in mitochondrial mass and metabolic rate [42]. However, it is possible to restore metabolic activity and organ function and is strongly regulated by expression of markers of mitochondrial biogenesis such as PPAR gamma-coactivator-1a (PGC-1a) and nuclear respiratory factors 1 and 2 (NRF-1 and -2) and via repression of the biogenesis suppressor nuclear receptor interacting protein-140 (RIP140) [50, 51]. Moreover, most recent preclinical studies have shown that not only preservation but also mitochondrial biogenesis is a key in recovering immune or tissue organ homeostasis during sepsis $[52,53]$.

\subsection{Diagnosis}

\subsubsection{Clinical Signs and Symptoms of Neonatal Sepsis}

Neonates with bacterial sepsis might exhibit nonspecific symptoms and symptoms and signs or focal signs of infection, including temperature instability, poor perfusion with pallor and mottled skin, cyanosis, hypotension, apnea, respiratory distress, grunting, tachycardia or bradycardia, metabolic acidosis, irritability, lethargy, seizures, abdominal distention, feeding intolerance, purpura, jaundice, petechiae, and bleeding (Table 16.1). Initial symptoms might be few and could include apnea alone or tachypnea with retractions, grunting, nasal flaring, or tachycardia. Later complications of sepsis might include pulmonary hypertension, respiratory failure, cardiac failure, renal failure, shock, cerebral or thrombosis, liver dysfunction, adrenal hemorrhage or insufficiency, bone marrow dysfunction (anemia, neutropenia, thrombocytopenia), and DIC. The manifestations of noninfectious organ failure may be similar to the clinical manifestations of neonatal sepsis. In addition, both infectious and noninfectious causes may be present at the same time. 
Table 16.1 Initial signs and symptoms of infection in newborn infants

\begin{tabular}{l|l}
\hline Symptoms & \\
\hline $\begin{array}{l}\text { General } \\
\text { Gastrointestinal } \\
\text { system }\end{array}$ & Fever, temperature instability; poor feeding, edema or "not doing well" \\
\hline Respiratory system & Apnea, tachypnea, dyspnea, flaring, retractions, grunting, or cyanosis \\
\hline Renal system & Oliguria \\
\hline $\begin{array}{l}\text { Cardiovascular } \\
\text { system }\end{array}$ & $\begin{array}{l}\text { Cold, clammy skin, pallor, mottling, tachycardia, bradycardia, or } \\
\text { hypotension }\end{array}$ \\
\hline CNS & $\begin{array}{l}\text { Irritability, lethargy, tremors, seizures, hypotonia, hyporeflexia, } \\
\text { abnormal Moro reflex, full fontanel, irregular respirations, or high- } \\
\text { pitched cry }\end{array}$ \\
\hline $\begin{array}{l}\text { Hematological } \\
\text { system }\end{array}$ & Jaundice, splenomegaly, pallor, petechiae, purpura, or bleeding \\
\hline
\end{tabular}

Adapted from Nelson Textbook of Pediatrics [54] with permission from Elsevier

\subsubsection{Conventional Diagnostics}

Traditionally, the diagnosis of neonatal sepsis depends on laboratory culture of isolating the causative agent from a normally sterile body site (blood, urine, CSF, and joint, pleural, and peritoneal fluids; Table 16.2). In order to optimize the diagnosis, it is necessary to obtain aseptic specimens of adequate volume. For blood culture, at least $0.5-1 \mathrm{~mL}$ of blood should be obtained, preferably from two different venipuncture sites. The true pathogens are more likely to be present in both cultures. In the presence of central venous catheters, it is best to simultaneously carry out blood cultures, one from a vascular catheter and the other from a peripheral blood, so that differential time to positivity can be assessed [55]. This helps to identify peripheral bacteremia and catheter-related bloodstream infections and is of significance for clinical management. Since certain pathogens may be detected only in cerebrospinal fluid but not in blood, sepsis assessment should also include a lumbar puncture procedure in symptomatic newborns. Automatic blood culture system continuously monitors the specimen and sends out an alarm when the positive signal is detected, thus facilitating the further processing of pathogen identification. Matrix-assisted laser desorption-ionization time-of-flight (MALDI-TOF) mass spectrometry can assist in the early identification of blood cultures and allow pathogen-targeted antibiotic treatment in the case of blood infections [56]. In recent years, multiple PCR techniques have been used to identify common bacteria and fungi, as well as drugresistant genes in blood culture-positive specimens within a few hours of organism growth. Similar techniques have been used in cerebrospinal fluid samples to shorten the time required for bacterial identification. Urinary tract infections do not occur in the first $72 \mathrm{~h}$ of life, so suprapubic bladder aspiration or catheterization is not done as part of the assessment of early neonatal sepsis. However, urinary tract infections are common in term and preterm infants and are an important source of late-onset sepsis in newborns [57]. Pathological examination of placenta may indicate chronic and acute intrauterine inflammation. Although placental cultures can detect 
Table 16.2 Culture-based and culture-independent diagnostics for neonatal sepsis (From Andi L Shane, Pablo J Sánchez, Barbara J Stoll. Neonatal sepsis. Lancet, 390, 10104-1770)

\begin{tabular}{|c|c|c|c|}
\hline & Parameter & $\begin{array}{l}\text { Optimal conditions for } \\
\text { specimen collection }\end{array}$ & $\begin{array}{l}\text { Applicability for } \\
\text { neonatal sepsis }\end{array}$ \\
\hline \multicolumn{4}{|l|}{ Culture-based } \\
\hline Blood & Culture & $\begin{array}{l}0.5-1 \mathrm{~mL} \text { of whole } \\
\text { blood from two sites at } \\
\text { time of symptom onset }\end{array}$ & $\begin{array}{l}\text { Gold standard for } \\
\text { bacteremia }\end{array}$ \\
\hline CSF & Culture & $\begin{array}{l}\text { When clinically feasible, } \\
>1 \mathrm{~mL} \text { CSF }\end{array}$ & $\begin{array}{l}\text { Optimize antimicrobial } \\
\text { therapy }\end{array}$ \\
\hline Urine & Culture & $\begin{array}{l}\text { At }>72 \mathrm{~h} \text { of life, }>1 \mathrm{~mL} \\
\text { urine }\end{array}$ & $\begin{array}{l}\text { Not useful for EOS; } \\
\text { potential benefits for } \\
\text { LOS }\end{array}$ \\
\hline $\begin{array}{l}\text { Tracheal } \\
\text { aspirate }\end{array}$ & Culture & $\begin{array}{l}\text { Obtained with concern } \\
\text { for new onset of lower } \\
\text { respiratory tract } \\
\text { infection }\end{array}$ & $\begin{array}{l}\text { Usually reflects } \\
\text { colonization }\end{array}$ \\
\hline \multicolumn{4}{|c|}{ Culture-independent } \\
\hline $\begin{array}{l}\text { Immune } \\
\text { function }\end{array}$ & MHC II and TNF- $\alpha$ & Investigational & $\begin{array}{l}\text { Both decreased in } \\
\text { chorioamnionitis and } \\
\text { sepsis }\end{array}$ \\
\hline $\begin{array}{l}\text { Neutrophil } \\
\text { indices }\end{array}$ & $\begin{array}{l}\text { Neutropenia a0bsolute } \\
\text { neutrophil count } \\
\text { Absolute immature } \\
\text { neutrophil count }\end{array}$ & $\begin{array}{l}\text { After } 12 \mathrm{~h} \text { of life, with } \\
\text { consideration of } \\
\text { gestational age, delivery } \\
\text { method, altitude, arterial } \\
\text { versus venous blood } \\
\text { sampling, and time since } \\
\text { birth }\end{array}$ & $\begin{array}{l}\text { Neutropenia better } \\
\text { predictor for sepsis than } \\
\text { leukocytosis }\end{array}$ \\
\hline $\begin{array}{l}\text { Neutrophil } \\
\text { markers }\end{array}$ & CD64 & $\begin{array}{l}\text { Increased for } 24 \mathrm{~h} \text { after } \\
\text { infection, requires } 50 \mu \mathrm{L} \\
\text { of blood, investigational }\end{array}$ & $\begin{array}{l}\text { Cutoff points between } \\
2.38 \text { and } 3.62 \text { optimal } \\
\text { sensitivity, specificity, } \\
\text { and NPV for EOS }\end{array}$ \\
\hline Platelet count & $\begin{array}{l}\text { Thrombocytopenia and } \\
\text { thrombocytosis }\end{array}$ & $\begin{array}{l}\text { Late findings occurring } \\
\text { after clinical } \\
\text { manifestations have } \\
\text { occurred, usually }>72 \mathrm{~h} \\
\text { after infection onset }\end{array}$ & $\begin{array}{l}\text { Thrombocytopenia } \\
\text { associated with fungal } \\
\text { infection }\end{array}$ \\
\hline CSF cell count & CSF WBC & $\begin{array}{l}\text { Uninfected neonates } \\
\text { mean } 10 \text { cells per } \mathrm{mm}^{3} \text {, } \\
\text { range up to } 20 \text { cells per } \\
\mathrm{mm}^{3}\end{array}$ & $\begin{array}{l}\text { Does not predict } \\
\text { culture-proven } \\
\text { meningitis }\end{array}$ \\
\hline $\begin{array}{l}\text { CSF } \\
\text { chemistries }\end{array}$ & $\begin{array}{l}\text { CSF protein and } \\
\text { glucose concentrations }\end{array}$ & $\begin{array}{l}\text { Full-term }<0.1 \mathrm{~g} / \mathrm{dL} \text {, } \\
\text { with preterm neonates } \\
\text { with higher } \\
\text { concentrations }(70-80 \% \\
\text { of serum glucose) }\end{array}$ & $\begin{array}{l}\text { Increased in fungal } \\
\text { meningitis; low glucose } \\
\text { specific for bacterial } \\
\text { meningitis }\end{array}$ \\
\hline $\begin{array}{l}\text { Acute phase } \\
\text { reactant- } \\
\text { CRP }\end{array}$ & CRP & $\begin{array}{l}\text { CRP assessed 8-24 h } \\
\text { after infection }\end{array}$ & Good NPV \\
\hline
\end{tabular}


Table 16.2 (continued)

\begin{tabular}{l|l|l|l}
\hline & Parameter & $\begin{array}{l}\text { Optimal conditions for } \\
\text { specimen collection }\end{array}$ & $\begin{array}{l}\text { Applicability for } \\
\text { neonatal sepsis }\end{array}$ \\
\hline $\begin{array}{l}\text { Acute phase } \\
\text { reactant- } \\
\text { procalcitonin }\end{array}$ & Procalcitonin & $\begin{array}{l}\text { Procalcitonin assessed } \\
\text { 2-12 h after infection, } \\
\text { investigational }\end{array}$ & $\begin{array}{l}\text { Better sensitivity but } \\
\text { less specificity than } \\
\text { CRP }\end{array}$ \\
\hline $\begin{array}{l}\text { Sepsis panels } \\
\text { scores }\end{array}$ & $\begin{array}{l}\text { Multiple laboratory } \\
\text { tests }\end{array}$ & $\begin{array}{l}\text { After } 24 \mathrm{~h} \text { of life, } \\
\text { investigational }\end{array}$ & $\begin{array}{l}\text { Most useful for NPV } \\
\text { and discontinuation of } \\
\text { antimicrobial therapy }\end{array}$ \\
\hline
\end{tabular}

Adapted from Nelson Textbook of Pediatrics [34] with permission from Elsevier. Routine refers to an assay or parameter that is usually available and widely used. Investigational refers to an assay or parameter that is undergoing assessment for clinical use and applicability

CSF cerebrospinal fluid, EOS early-onset sepsis, LOS late-onset sepsis, MHCII major histocompatibility complex class II, $T N F-\alpha$ tumor necrosis factor $\alpha, N P V$ negative predictive value, $W B C$ white blood cell count, $C R P$ C-reactive protein

potentially pathogenic bacteria, these findings do not indicate that the fetus has come into contact with the pathogen, nor is it a true infection, so this should not be a reason for long-term antibiotic therapy in infants.

\subsubsection{Culture-Independent Diagnostics}

Because PCR is a highly sensitive and rapid technique, it is increasingly being applied to bodily fluids directly without the need to first culture causative agents (Table 16.2). Quantitative real-time amplification systems (qPCR) based on bacterial 16S ribosomal DNA have a very high negative predictive value, and results are usually available in a timely manner. Additionally, a small volume sample is frequently sufficient, and the test can be done on surgical tissues and body fluids such as pleural effusions and ascites. Disadvantages of qPCR include the inability to do susceptibility testing and a high sensitivity that does not differentiate between active infection and recent infections that have resolved [58]. The possibility of detecting contaminants is also high, and therefore clinical correlation with results is mandatory. Other commonly used non-culture-based diagnostic tests include the total and differential white blood cell (WBC) count, absolute and immature neutrophil counts, and the ratio of immature to total neutrophils (I/T). Although the WBC count has limitations in terms of sensitivity, an immature-to-total neutrophil ratio of 0.2 or greater has been suggestive of a bacterial infection. The I/T score was found to be predictive when used in combination with complete blood cell counts obtained at more than $4 \mathrm{~h}$ of age [59]. However, abnormal WBC counts could also result from fetal exposure to in utero inflammation and not sepsis as frequently seen following maternal chorioamnionitis. It seems that the main benefit of the WBC count is its negative predictive value since normal serial values make it unlikely that a blood or CSF culture will be positive. It is also worth noting that WBC values are dynamic during the first $12 \mathrm{~h}$ of life, so serial measurements over $24 \mathrm{~h}$ might be more informative than a single assessment. Other diagnostic tests that measure an 
inflammatory response include CRP, procalcitonin (PCT), haptoglobin, fibrinogen, proteomic markers in amniotic fluid, inflammatory cytokines (including IL-6, IL-8, and TNF- $\alpha$ ), and cell surface markers (including soluble CD14 subtype [presepsin], and neutrophil CD64) [60, 61]. CRP is commonly used as a marker of bacterial infection. Because of the need to synthesize CRP in the liver before obvious concentrations were found, serum CRP increases within 6-10 h after infection and reached a peak at 2-3 days after infection, resulting in a decrease in sensitivity. Serum PCT increases within $4 \mathrm{~h}$ and peaks at 18 and $24 \mathrm{~h}$ after onset of the disease. Continuous detection of CRP and other acute phase reactants and markers, such as PCT and interleukin (IL-6) and interleukin (IL-8), may improve the accuracy of the diagnosis of infection $[62,63]$. Similar to the WBC count, these nonspecific inflammatory markers have a high negative predictive value if there are no continuous abnormalities, supporting the cessation of antibiotic therapy.

\subsubsection{Novel Diagnostic Approaches to Neonatal Sepsis}

\subsubsection{Cord Blood}

The cell composition of umbilical cord blood is similar to that of the peripheral blood of fetus during last stage of gestation. It is the first hematologic source from the neonate. It does not require invasive operation nor cause the newborn to feel pain, so the collection of specimens avoids the iatrogenic complications. It also gets more blood, which helps reduce iatrogenic blood loss and does not lead to hemodynamic instability in the newborn. A study analyzing 350 pairs of samples from peripheral venous and umbilical cord samples found a significant correlation between leukocyte and platelet counts (correlation coefficients $r=0.683$ and $r=0.54$, respectively) and a lower correlation between hemoglobin ( $r=0.36)$ [64]. This may be explained because cord blood from a premature infant may not be the same as the peripheral blood of a premature baby. Although no cases of EOS were detected, the contamination rate of cord blood was higher than that of peripheral blood (12\% vs 2.5\%) [64]. Another study involving 200 newborns found that cord blood samples had a low contamination rate of just $0.5 \%$ [65]. This study confirmed that hematocrit, platelets, WBC, and ANC have similarities between cord and peripheral blood. A study assessing 40 newborns with 2 or more risk factors for EOS found that cord blood had $100 \%$ sensitivity and $95 \%$ specificity compared to the peripheral blood. However, cord blood CRP was negative in all 11 neonates with positive screening for sepsis [66]. Another review of 15 studies evaluating more than 2000 episodes of suspected neonatal infection identified PCT and IL-6 in cord blood as having high positive (5.72 and 9.47, respectively) and negative likelihood ratios (0.20 and 0.10 , respectively) [67].

\subsubsection{Novel Biomarkers}

Proteomics is a new field of research in the post-genetic age. Proteomics is used to isolate and identify differentially expressed proteins in body fluids (mainly blood and urine) from patients with sepsis, which can help to find the biomarkers for the 
early diagnosis of sepsis, and has important significance for the early diagnosis, disease monitoring, prognosis evaluation, the pathogenesis of sepsis, and the discovery of drug targets [68]. Based on proteomic analyses, a mass restricted scoring strategy has been devised using relevant proteomic biomarkers. These measurements of amniotic fluid have provided information regarding the fetal response to intra-amniotic inflammation and have successfully predicted EOS with $>92 \%$ accuracy $[69,70]$. On the basis of proteomics analysis, a large-scale restricted scoring strategy was designed by using the related proteomic biomarkers. The proteome analysis of amniotic fluid provided a wealth of information about the fetus's response to intra-amniotic inflammation and successfully predicted EOS with more than $92 \%$ accuracy. Altered protein expression patterns have been found through proteomics analysis of cord blood. In a prospective cohort study, a proteomics approach identified biomarkers that were validated and identified two promising biomarkers in proapolipoprotein CII and a des-arginine variant of serum amyloid A [71]. When infants were stratified by risk category based on a score computed using these two concentrations, these markers might play an important role in guiding antimicrobial management decisions and excluded sepsis with $100 \%$ negative predictive value [71]. Metabonomics is a newly developed discipline after genomics and proteomics. It is an important part of systems biology. Metabonomics is the study of individual metabolic profiles. The increase of some metabolites can be detected in patients with sepsis, which has a very good diagnostic value [72]. A study found that the combined use of $1 \mathrm{H}-\mathrm{NMR}$ and GC-MS to analyze the metabolic profile of the urine fluid of newborns can effectively distinguish infection from non-infection and also distinguish between early and late neonatal sepsis [73].

\subsection{Management}

\subsubsection{Fluid Resuscitation}

Hypovolemia is common in neonatal sepsis and is associated with poor prognosis. Hypovolemia can be divided into absolute deficiency (loss of blood volume) and relative deficiency (redistribution of blood volume). There is redistribution of blood volume in neonatal sepsis. Fluid resuscitation plays an important role in neonates. The pathophysiological changes of neonatal sepsis are different from those of adults, which are characterized by increased systemic vascular resistance and decreased cardiac output (cold shock). Because the children body surface area is relatively large, the loss of water is relatively more, and the fluid resuscitation treatment can be better tolerance to a little more liquid [74]. Resuscitation volume at $1 \mathrm{~h}$ is $10-60 \mathrm{~mL} / \mathrm{kg}$ to maintain normal perfusion and blood pressure in full-term infants, while liver enlargement and dyspnea should be observed. In preterm infants, there is not enough evidence that a large-volume fluid resuscitation can achieve effects similar to those of full-term infants. For preterm infants with low blood pressure, $10-20 \mathrm{~mL} / \mathrm{kg}$ saline is recommended within the $30-60 \mathrm{~min}$. This more cautious approach attributed to reports that rapid changes of blood pressure in premature infants of less than 30 weeks could increase the risk of cerebral hemorrhage [75] . 


\subsubsection{Treatment Against Infectious Agents}

\subsubsection{Therapy for the Suspected Pathogens}

The timing of antibiotic therapy for patients with sepsis has been shown to be a key factor in the survival, and several studies have shown that delays in appropriate antibiotic therapy are associated with increased mortality in patients with sepsis and septic shock. It is essential to draw blood for culture before antibiotics are used. But blood culture is of low sensitivity and takes a long time, which is easy to delay treatment. In addition, we should not excessively delay the use of antibiotics in critical neonates with sepsis because of the collection of specimens. In general, empirical treatment should be guided by common antimicrobial resistance patterns of bacterial isolates in community settings or neonatal intensive care units. Ampicillin and third- or fourth-generation cephalosporins are primary empirical treatments for early-onset bacterial infections and can be used in suspected Gram-negative meningitis. Infections caused by extended-spectrum $\beta$-lactamase-producing Gramnegative bacilli require treatment with carbapenems, such as meropenem. Treatment with ampicillin-sulbactam and piperacillin-tazobactam is being used increasingly among infants admitted to hospital in the NICU; however, since tazobactam does not easily penetrate into the central nervous system, it should not be used in the treatment of meningitis. However, the $\beta$-lactamase inhibitor sulbactam in combination with ampicillin does seem to achieve high concentrations in the CSF (Table 16.3). Although bloodstream infections caused by coagulase-negative

Table 16.3 Management and prevention of neonatal sepsis (From Andi L Shane, Pablo J Sánchez, Barbara J Stoll. Neonatal sepsis. Lancet, 390, 10104-1770)

\begin{tabular}{|c|c|c|}
\hline & Therapy & Additional considerations \\
\hline \multicolumn{3}{|c|}{ Empirical management } \\
\hline EOS & $\begin{array}{l}\text { Ampicillin plus } \\
\text { aminoglycoside; } 10 \text { days for } \\
\text { bacteremia; } 14 \text { days for GBS } \\
\text { bacteremia and uncomplicated } \\
\text { meningitis; extend to } \\
21-28 \text { days for complicated } \\
\text { infections }\end{array}$ & $\begin{array}{l}\text { Consider a third-generation } \\
\text { cephalosporin (cefotaxime preferred) } \\
\text { or carbapenem for meningitis; tailor } \\
\text { therapy to pathogen; consider } \\
\text { discontinuation of therapy if pathogen } \\
\text { not isolated }\end{array}$ \\
\hline LOS & $\begin{array}{l}\text { Vancomycin plus } \\
\text { minoglycoside; duration of } \\
\text { treatment dependent on } \\
\text { pathogen and site }\end{array}$ & $\begin{array}{l}\text { Alternatives to vancomycin can be } \\
\text { considered on the basis of local } \\
\text { epidemiology and clinical presentation; } \\
\text { an aminoglycoside-based regimen is } \\
\text { preferred to cephalosporin given the } \\
\text { reduced risk of resistance; consider } \\
\text { cephalosporin if meningitis is } \\
\text { suspected, a carbapenem if the patient } \\
\text { has recently been given a third- } \\
\text { generation cephalosporin, and } \\
\text { amphotericin for fungal causes, and } \\
\text { tailor therapy to pathogen, and } \\
\text { consider discontinuation of therapy if } \\
\text { pathogen is not isolated }\end{array}$ \\
\hline
\end{tabular}


Table 16.3 (continued)

\begin{tabular}{|c|c|c|}
\hline & Therapy & Additional considerations \\
\hline \multicolumn{3}{|c|}{ Non-antimicrobial treatment strategies } \\
\hline $\begin{array}{l}\text { Recombinant } \\
\text { G-CSF and } \\
\text { recombinant } \\
\text { GM-CSF }\end{array}$ & $\begin{array}{l}\text { Enhance neutrophil number } \\
\text { and function, but no reduction } \\
\text { in infection when administered } \\
\text { as prophylaxis or improvement } \\
\text { in survival when administered } \\
\text { as therapy }\end{array}$ & $\begin{array}{l}\text { Insufficient evidence to support the } \\
\text { clinical use of G-CSF or GM-CSF } \\
\text { either as treatment or prophylaxis to } \\
\text { prevent systemic infections }\end{array}$ \\
\hline IVIG & $\begin{array}{l}\text { Augments antibody-dependent } \\
\text { cytotoxicity and improves } \\
\text { neutrophilic function but no } \\
\text { evidence that IVIG in } \\
\text { suspected or proven sepsis } \\
\text { reduces death }\end{array}$ & $\begin{array}{l}\text { Insufficient evidence from } 10 \text { RCTs or } \\
\text { quasi-RCTs to support use in neonates } \\
\text { with confirmed or suspected sepsis }\end{array}$ \\
\hline \multicolumn{3}{|c|}{ Prevention strategies } \\
\hline IAP & $\begin{array}{l}\text { Administration of penicillin or } \\
\text { ampicillin } 4 \mathrm{~h} \text { before } \\
\text { parturition }\end{array}$ & $\begin{array}{l}\text { Successfully reduces rates of EOS due } \\
\text { to GBS; and no effect on LOS GBS }\end{array}$ \\
\hline $\begin{array}{l}\text { Fluconazole } \\
\text { prophylaxis }\end{array}$ & $\begin{array}{l}\text { Administration of weight- } \\
\text { based dosing to neonates less } \\
\text { than } 1500 \mathrm{~g}\end{array}$ & $\begin{array}{l}\text { Most beneficial in NICUs with high } \\
\text { baseline rates of invasive candidiasis }\end{array}$ \\
\hline $\begin{array}{l}\text { BLF } \\
\text { supplementation } \\
\text { with a probiotic, } \\
\text { LGG }\end{array}$ & $\begin{array}{l}\text { BLF is a human milk } \\
\text { glycoprotein with a role in } \\
\text { innate immune response. LGG } \\
\text { enhances the activity of } \\
\text { lactoferrin }\end{array}$ & $\begin{array}{l}\text { BLF supplementation with and without } \\
\text { LGG reduced the incidence of first } \\
\text { LOS in } 472 \text { VLBW neonates in large } \\
\text { randomized, double-blind } \\
\text { RCT. Additional confirmatory studies } \\
\text { warranted }\end{array}$ \\
\hline
\end{tabular}

No recommended durations are provided for non-antimicrobial therapies since there is insufficient evidence for their use. Adapted from Nelson Textbook of Pediatrics [34] with permission from Elsevier

EOS early onset sepsis, GBS group B streptococcus, LOS late-onset sepsis, IVIG intravenous immunoglobulin, $R C T$ randomized controlled trials, IAP intrapartum antimicrobial prophylaxis, $N I C U$ neonatal intensive care unit, G-CSF granulocyte colony stimulating factor, GM-CSF granulocyte macrophage stimulating factor, $B L F$ bovine lactoferrin supplementation, $L G G$ Lactobacillus rhamnosus GG, $V L B W$ very low birthweight

staphylococci in premature infants are associated with a high number of short-term morbidity and long-term neurodevelopmental disorders, they are not associated with increased mortality. The use of broad-spectrum antibiotics can cause some additional damages, including overgrowth of potentially pathogenic intestinal flora. The intestinal flora can change in a matter of days. Antibiotics can turn bacteria in the gut or elsewhere into drug-resistant bacteria. So we should always weigh the pros and cons of antibiotics. Long-course antibiotics are often unhelpful and can cause drug-resistant bacteria to overgrow beyond the normal colonization of symbiotic colonies. Fungal infections including candidiasis, zygomycoses, and aspergillosis should be treated actively when they are suspected and diagnosed. Newborns belong to a special group, which is a high incidence of fungal sepsis. In the NICU, newborns belong to a special group, which is a high incidence of fungal sepsis; the 
incidence was $1.2 \%$ in all hospitalized newborns, $3.1 \%$ in very low birth weight, and $5.5 \%$ in extremely low birth weight, and the mortality of infected infants was $22.9 \%$. Premature/low birth weight, endotracheal intubation and mechanical ventilation, long duration of antibiotic use, and long hospital stay were risk factors. Empirical antifungal therapy with amphotericin deoxycholate can be feasible for infants at high risk for invasive candidiasis. In order to optimize the use of antimicrobials, a pharmacist with expertise in neonatal infections and a pediatric infectious disease doctor are required to participate in the development of treatment programs. Blood concentrations of antifungal drugs should be monitored to improve the efficacy of drug treatment or reduce toxicity of drugs if these drugs are used for more than 2-3 days. Antibiotics can be safely stopped at 48-72 h in neonates with negative blood cultures who are clinically stable [76]. Around $90 \%$ of positive blood cultures grow by $48 \mathrm{~h}$ and $97 \%$ by $72 \mathrm{~h}$. Most cultures that turn positive after $72 \mathrm{~h}$ are contaminants [77]. Discontinuation of antibiotics after the blood culture is reported negative at $48 \mathrm{~h}$ in clinically stable newborns and does not increase treatment failure [78]. Continuous CRP detection plays an important role in guiding and shortening the duration of antibiotic therapy [76]. The single and continuous values $24 \mathrm{~h}$ after the onset of symptoms had higher negative predictive values (98-100\%) [79]. However, a recent study found that the negative predictive value of CRP at $48 \mathrm{~h}$ was only $86 \%$ [80]. Previous studies have ruled out high-risk babies, such as those with centerline, asphyxia, or mechanical ventilation. The value of CRP in guiding antimicrobial therapy may be limited to a selected population [76]. I/T scores and procalcitonin have also been used to guide treatment with encouraging results, but there's still a need for a large clinical trial [81, 82].

\subsubsection{Therapy for the Known Pathogens}

Once the pathogen of neonatal sepsis is identified, antibiotics that are sensitive to the pathogen should be used as early as possible. Penicillin or ampicillin is effective against GBS and can be discontinued if blood and CSF cultures are sterile. Enterococci should be treated with a penicillin-containing antibiotic, with the addition of an aminoglycoside if synergy is documented to provide bactericidal and post-antibiotic effects. Infections due to ampicillin-resistant enterococci are treated with vancomycin without the addition of an aminoglycoside. Ampicillin alone is effective against L-monocytogenes, although the aminoglycoside also provides synergy at treatment onset. For Gram-negative enteric bacteria, an aminoglycoside or ampicillin (if susceptible) is sufficient for treatment. However, if meningitis is suspected or confirmed, a third-generation or fourth-generation cephalosporin or carbapenem agent should be used. Invasive infections caused by extended-spectrum $\beta$-lactamase (ESBL)-producing Enterobacteriaceae spp. are best treated with a carbapenem treatment, although cefepime might also be effective. Metronidazole, ampicillin-sulbactam, clindamycin, and metronidazole are effective for anaerobic infections; metronidazole is the first choice for anaerobic infections associated with the CNS. Because most of coagulase-negative staphylococci and MRSA are resistant to $\beta$-lactam antibiotics, vancomycin should be used empirically. Teicoplanin, as a new generation glycopeptide antibiotic, is recommended for newborns who 
cannot tolerate vancomycin. It has the same efficacy as vancomycin but has less side effects. Amphotericin deoxycholat is still the first choice for invasive candidiasis when meningitis may exist; liposome amphotericin or hydatid (Caspofungin or micafungin) is the best choice for hepatic or splenic candidiasis. Fluconazole may be an effective drug for susceptible organisms. If the infection is associated with central venous catheter access, successful treatment outcomes depend on the duration of positive cultures, underlying condition of the host infant, and ability to remove the source. The exact duration of antimicrobial therapy is not supported by sufficient evidence; however, at a minimum, antibiotics should be discontinued if the cultures are sterile and clinical recovery is evident. It used to be thought that the duration of antibiotic therapy was 7 days for bloodstream infections, 14 days for Gram-positive meningitis, and 21 days for Gram-negative meningitis. However, prolonged use of antibiotics often leads to bacterial resistance, such as the widespread use of vancomycin, which has led to the emergence of vancomycininsensitive Staphylococcus aureus and vancomycin-resistant Enterococcus. Interestingly, a study has found that 5 days of ceftriaxone was sufficient to cure bacterial meningitis caused by Neisseria meningitidis, Haemophilus influenzae type b, and Streptococcus pneumoniae [83]. Infants who have been exposed to antibiotics have been shown to have higher rates of necrotizing enterocolitis, sepsis, and morbidity than infants who have not been exposed to antibiotics, presumably due to intestinal dysbiosis induced by antibiotic exposure [84].

In summary, based on our experience, our principles for the use of antibiotics in neonatal sepsis include the following: (1) antibiotics should be used early in the newborns who have highly suspected or proven infection, (2) early discovery of the source of infection is the key to effective treatment, (3) anti-infection and fluid resuscitation should be carried out simultaneously, (4) antibiotics can only kill pathogens but cannot correct immune disorder, and (5) if the evidence of infection does not exist, antibiotics should be discontinued in time.

\subsubsection{Restoring Immune Balance}

In neonatal sepsis, the innate immune system and the innate immune cells are overactivated, leading to severe and persistent inflammation. A large number of cytokines and inflammatory mediators, such as IL-1, IL-6, IL-17, and TNF- $\alpha$, were uncontrollably produced in a short period of time. This systemic inflammatory process can result in MODS and death. Therefore, it is important to control the inflammatory response in the early stages of sepsis. However, all RCTs on anti-IL-1, anti-IL-10, anti-PAF, recombinant human soluble thrombomodulin, and recombinant bactericidal permeability-increasing protein (BPI) were negative [84-86]. Some molecules were detrimental, like recombinant tissue factor pathway inhibitor and nitric oxide synthase inhibitors [87]. Recent studies demonstrated that a long-term immunosuppression was a major reason for the high mortality rate in long-term outcomes. Understanding immunodynamics of sepsis 
and its immunosuppression is very important to decrease mortality. Hyperinflammation is in the early stage of the immunodynamics of sepsis. The exorbitant release of inflammatory mediator and cytokines impairs tissue cells in inflammatory reaction and, at the same time, also causes immune cells damage and immune suppression consequently, which is the basis of sepsis immunosuppression. Middle stage of sepsis is mixed immune status. During this period, inflammatory and anti-inflammatory mechanism competes with each other, while the inflammatory lesions continue and immune function is further restrained. In the later stage of sepsis, further deterioration and severer immunosuppression leads to immunoparalysis in the end. So far, there is no effective treatment for immunosuppression or immunoparalysis of sepsis. Including glucocorticoid, nonsteroid anti-inflammatory drug, TNF-a antibodies, IL-1 antagonists, and so on, a meta-analysis reported that the different types of colony-stimulating factors (CSFs) seem to be ineffective for neonatal sepsis [88], as were granulocyte-CSF (G-CSF) and granulocyte-macrophage CSF (GM-CSF). Immune globulins (IVIG) are effective in adults with sepsis [89] but not in newborns with gestational ages of 31-42 week [90] or low birth weight newborns $(<1500 \mathrm{~g})$ [91]. At present, it is now believed that the control of the early inflammatory reaction is the key to preventing immunosuppression or immunoparalysis of sepsis. The main approaches include timely detection and diagnosis of sepsis, rational use of antibiotics, adequate fluid resuscitation, improvement of microcirculation, and so on. Meanwhile, the occurrence of iatrogenic immune disorder should be avoided as far as possible. Extracorporeal blood purification techniques have the functions of clearing toxins and inflammatory factors, stabilizing hemodynamics, regulating liquid balance, and so on. It can also be used in the treatment of sepsis complicated with shock and acute respiratory distress syndrome (ARDS). A meta-analysis of RCTs reported that, overall, hemoperfusion; blood purification techniques, hemofiltration and hemodialysis; and plasma exchange decrease the mortality rate of patients with sepsis (RR0.69, 95\%CI, 0.56-0.84). The most positive effect was attributable to two RCTs on plasma exchange (RR 0.63, 95\% CI 0.42-0.96) and ten RCTs on polymyxin B hemoperfusion (RR 0.63, 95\% CI, 0.50-0.80) [92]. The efficacy of blood purification techniques must be estimated by a large RCT before they can be strongly recommended [93]. The cost/benefit ratio of the technologies for newborns and infants should be fully assessed since the risk of mortality in this population is much lower than in adults. At the same time, it is often difficult because of the need to quickly establish vascular access [94].

\subsubsection{Supportive Care}

The rapid identification of neonatal sepsis is the key to successful treatment, because the blood pressure in the early stage of neonatal sepsis does not decrease and may even increase. A detailed physical examination that includes normal peripheral pulses, capillary refill of not more than $2 \mathrm{~s}$, urine output of more than 
$1 \mathrm{~mL} / \mathrm{kg} / \mathrm{h}$, or normal mental status may be more reliable than blood pressure. In cases of refractory shock, albumin can be given. Hydrocortisone is also an option for the treatment of children with fluid- and catecholamine-resistant shock and suspected or proven adrenal insufficiency, although its efficacy remains to be determined. Blood glucose control and vasopressin are also proposed, but two RCT studies in children have failed to demonstrate any clinical benefit of tight blood glucose control (4.0-7.0 $\mathrm{mmol} / \mathrm{L}$ versus less than $12.0 \mathrm{mmol} / \mathrm{L})$ [95] and vasopres$\sin [96]$. Once the shock is resolved, patients with refractory fluid overload ( $>10 \%)$ can be treated with continuous veno-venous hemofiltration or intermittent hemodialysis. Early goal-directed therapy (EGDT) has been considered as an important method to reduce mortality through the use of invasive monitoring measures to mediate fluid resuscitation in patients with septic shock and has been recommended by international guidelines such as the "Surviving Sepsis Campaign." In recent years, large-scale multicenter studies suggested that EGDT strategy could not reduce the mortality of the patients with severe sepsis and septic shocks and may bring some adverse effects. However, early fluid resuscitation and monitoring is still an important means of treatment of septic shock; therefore, EGDT is still have some value. In children, a RCT study involving 102 Brazilian children with severe sepsis or fluid refractory shock found that the goal and bundle could reduce mortality by $11.8 \%$ compared with $39.2 \%$ in the control group. AS very few newborns were enrolled in the study; the prevalence of neonatal sepsis would need to be confirmed [97]. Improving oxygen delivery is one of the central goals of supportive care; it is usually achieved by increasing the hemoglobin level. However, RBC transfusions are not completely safe [98]. We do not know the optimal RBC infusion threshold in patients with sepsis, especially for unstable patients. A clinical analysis involving 137 patients with sepsis suggests that restrictive erythrocyte transfusion strategies (hemoglobin threshold values of $7 \mathrm{~g} / \mathrm{dL}$ ) may be safe in stable or stabilized children and neonates with sepsis, even if they are in septic shock [99]. However, RBC transfusion needs in unstable neonates and infants with sepsis still remain unclear.

\subsection{Conclusion}

Neonatal sepsis has higher morbidity and mortality rate especially in developing countries. The susceptibility of neonates, pathogen variability between different regions, complex pathogenesis, and lack of consensus in the definitions obstruct the development of clinical trials and practice guidelines. Physicians face multiple problems in diagnosis and treatment decisions. Most of them feel stressed enough to treat every newborn with suspected sepsis. Therefore many newborns receive prolonged antibiotic therapies, which often lead to many new complications. In fact, comprehensive preventive strategies are very important, including hand hygiene, early breastfeeding, reducing unnecessary operations, the limitation of indwelling devices, etc. Beyond that, we should follow the pathogenesis of neonatal sepsis and develop individualized treatment plan in order to a good outcome. 


\section{References}

1. Singer M, Deutschman CS, Seymour CW, et al. The third international consensus definitions for sepsis and septic shock (Sepsis-3). JAMA. 2016;315(8):801-10.

2. Wynn JL. Defining neonatal sepsis. Curr Opin Pediatr. 2016;28(2):135-40.

3. Liu L, Johnson HL, Cousens S, Perin J, Scott S, Lawn JE, et al. Global, regional, and national causes of child mortality: an updated systematic analysis for 2010 with time trends since 2000. Lancet. 2012;379(9832):2151-61.

4. Brocklehurst P, Farrell B, King A, Juszczak E, Darlow B, Haque K, et al. Treatment of neonatal sepsis with intravenous immune globulin. N Engl J Med. 2011;365(13):1201-11.

5. Stoll BJ, Hansen NI, Bell EF, Shankaran S, Laptook AR, Walsh MC, et al. Neonatal outcomes of extremely preterm infants from the NICHD Neonatal Research Network. Pediatrics. 2010;126(3):443-56.

6. Cohen-Wolkowiez M, Moran C, Benjamin DK, Cotten CM, Clark RH, Benjamin DK Jr, et al. Early and late onset sepsis in late preterm infants. Pediatr Infect Dis J. 2009;28(12):1052-6.

7. Barton L, Hodgman JE, Pavlova Z. Causes of death in the extremely low birth weight infant. Pediatrics. 1999;103(2):446-51.

8. Stoll BJ, Hansen NI, Adams-Chapman I, Fanaroff AA, Hintz SR, Vohr B, et al. Neurodevelopmental and growth impairment among extremely low-birth-weight infants with neonatal infection. JAMA. 2004;292(19):2357-65.

9. Jan AI, Ramanathan R, Cayabyab RG. Chorioamnionitis and management of asymptomatic infants $\geq 35$ weeks without empiric antibiotics. Pediatrics. 2017;140(1):e20162744.

10. Verani JR, McGee L, Schrag SJ, Division of Bacterial Diseases NCfIaRD, Centers for Disease Control and Prevention (CDC). Prevention of perinatal group B streptococcal disease-revised guidelines from CDC, 2010. MMWR Recomm Rep. 2010;59:1-36.

11. Kaufman DA, Coggins SA, Zanelli SA, Weitkamp JH. Congenitalcutaneous candidiasis: rompt systemic treatment is associated withimproved outcomes in neonates. Clin Infect Dis. 2017;64(10):1387-95.

12. Barton M, Shen A, O'Brien K, Robinson JL, Davies HD, Simpson K, et al. Early onset invasive candidiasis in extremely low birthweight infants: perinatal acquisition predicts poor outcome. Clin Infect Dis. 2017;64(7):921-7.

13. Vergnano S, Menson E, Smith Z, Kennea N, Embleton N, Clarke P, et al. Characteristics of invasive Staphylococcus aureus in United Kingdom Neonatal Units. Pediatr Infect Dis J. 2011;30:850-4.

14. Investigators of the Delhi Neonatal Infection Study (DeNIS)collaboration. Characterisation and antimicrobial resistance of sepsis pathogens in neonates born in tertiary care centres in Delhi, India: a cohort study. Lancet Glob Health. 2016;4:e752-60.

15. Kimberlin DW, Whitley RJ, Wan W, Powell DA, Storch G, Ahmed A, et al. Oral acyclovir suppression and neurodevelopment after neonatal herpes. N Engl J Med. 2011;365:1284-92.

16. Thompson C, Whitley R. Neonatal herpes simplex virus infections: where are we now? Adv Exp Med Biol. 2011;697:221-30.

17. Verboon-Maciolek MA, Krediet TG, Gerards LJ, de Vries LS, Groenendaal F, van Loon AM. Severe neonatal parechovirus infection and similarity with enterovirus infection. Pediatr Infect Dis J. 2008;27:241-5.

18. Trofa D, Gácser A, Nosanchuk JD. Candida parapsilosis, anemerging fungal pathogen. Clin Microbiol Rev. 2008;21:606-25.

19. Benjamin DK Jr, Stoll BJ, Gantz MG, Walsh MC, Sánchez PJ, Das A, et al. Neonatal candidiasis: epidemiology, risk factors, and clinical judgment. Pediatrics. 2010;126:e865-73.

20. Chan GJ, Lee ACC, Baqui AH, Tan J, Black RE. Risk of early-onset neonatal infection with maternal infection or colonization: a global systematic review and meta-analysis. PLoS Med. 2013;10:e1001502.

21. Jiang Z, Ye GY. 1:4 matched case-control study on influential factor of early onset neonatal sepsis. Eur Rev Med Pharmacol Sci. 2013;17:2460e6. 
22. Mukhopadhyay S, Puopolo KM. Risk assessment in neonatal early onset sepsis. Semin Perinatol. 2012;36:408e15.

23. Weston EJ, Pondo T, Lewis MM, Martell-Cleary P, Morin C, Jewell B, et al. The burden of invasive early-onset neonatal sepsis in the United States, 2005-2008. Pediatr Infect Dis J. 2011;30:937-41.

24. Schuchat A, Zywicki SS, Dinsmoor MJ, Mercer B, Romaguera J, O’Sullivan MJ, et al. Risk factors and opportunities for prevention of early-onset neonatal sepsis: a multicenter casecontrol study. Pediatrics. 2000;105(1 Pt 1):21-6.

25. Wynn JL, Levy O. Role of innate host defenses in susceptibility to early-onset neonatal sepsis. Clin Perinatol. 2010;37:307e37.

26. Stoll BJ, Hansen NI, Higgins RD, Fanaroff AA, Duara S, Goldberg R, et al. Very low birth weight preterm infants with early onset neonatal sepsis: the predominance of gram-negative infections continues in the National Institute of Child Health and Human Development Neonatal Research Network, 2002-2003. Pediatr Infect Dis J. 2005;24:635-9.

27. Stoll BJ, Hansen N, Fanaroff AA, Wright LL, Carlo WA, Ehrenkranz RA, et al. Late-onset sepsis in very low birth weight neonates: the experience of the NICHD Neonatal Research Network. Pediatrics. 2002;110:285-91.

28. Samuelsson A, Isaksson B, Hanberger H, Olhager E. Late-onset neonatal sepsis, risk factors and interventions: an analysis of recurrent outbreaks of Serratia marcescens, 2006-2011. J Hosp Infect. 2014;86:57-63.

29. Hoffman MA, Snowden JN, Simonsen KA, Nenninger TM, Lyden ER, Anderson-Berry AL. Neonatal late-onset sepsis following peripherally inserted central catheter removal: association with antibiotic use and adverse line events. J Infus Nurs. 2015;38:129-34.

30. Janeway CA Jr, Medzhitov R. Innate immune recognition. Annu Rev Immunol. 2002;20:197-216.

31. Akira S, Uematsu S, Takeuchi O. Pathogen recognition and innate immunity. Cell. 2006;124(4):783-801.

32. de Backer D, Creteur J, Preiser JC, Dubois MJ, Vincent JL. Microvascular blood flow is altered in patients with sepsis. Am J Respir Crit Care Med. 2002;166(1):98-104.

33. Trzeciak S, Dellinger RP, Parrillo JE, Guglielmi M, Bajaj J, Abate NL, et al. EarlyMicrocirculatory perfusion derangements in patients with severe sepsis and septic shock:Relationship to hemodynamics, oxygen transport, and survival. Ann Emerg Med. 2007;49(1):88-98, 98 e81-82

34. Sakr Y, Dubois MJ, de Backer D, Creteur J, Vincent JL. Persistent microcirculatory alterations are associated with organ failure and death in patients with septic shock. Crit Care Med. 2004;32(9):1825-31.

35. Ince C. The microcirculation is the motor of sepsis. Crit Care. 2005;9(Suppl 4):S13-9.

36. Spronk PE, Zandstra DF, Ince C. Bench-to-bedside review: sepsis is a disease of the microcirculation. Crit Care. 2004;8(6):462-8.

37. Ait-Oufella H, Maury E, Lehoux S, Guidet B, Offenstadt G. The endothelium: physiological functions and role in microcirculatory failure during severe sepsis. Intensive Care Med. 2010;36(8):1286-98.

38. Chan DC. Mitochondria: dynamic organelles in disease, aging, and development. Cell. 2006;125:1241-52.

39. Osellame LD, Blacker TS, Duchen MR. Cellular and molecular mechanisms of mitochondrial function. Best Pract Res Clin Endocrinol Metab. 2012;26:711-23.

40. Singer M. Mitochondrial function in sepsis: acute phase versus multiple organ failure. Crit Care Med. 2007;35(9 Suppl):S441-8.

41. Larsen FJ, Schiffer TA, Weitzberg E, Lundberg JO. Regulation of mitochondrial function and energetics by reactive nitrogen oxides. Free Radic Biol Med. 2012;53:1919-28.

42. Haden DW, Suliman HB, Carraway MS, Welty-Wolf KE, Ali AS, Shitara H, et al. Mitochondrial biogenesis restores oxidative metabolism during Staphylococcus aureus sepsis. Am J Respir Crit Care Med. 2007;176:768-77. 
43. Singer M. The role of mitochondrial dysfunction in sepsis-induced multi-organ failure. Virulence. 2014;5:66-72.

44. Carré JE, Orban JC, Re L, Felsmann K, Iffert W, Bauer M, et al. Survival in critical illness is associated with early activation of mitochondrial biogenesis. Am J Respir Crit Care Med. 2010;182:745-51.

45. Mayr FB, Yende S, Angus DC. Epidemiology of severe sepsis. Virulence. 2014;5:4-11.

46. Ferro TN, Goslar PW, Romanovsky AA, Petersen SR. Smoking in trauma patients: the effects on the incidenceof sepsis, respiratory failure, organ failure, and mortality. J Trauma. 2010;69:308-12.

47. Huttunen R, Laine J, Lumio J, Vuento R, Syrjänen J. Obesity and smoking are factors associated with poor prognosis in patients with bacteraemia. BMC Infect Dis. 2007;7:13.

48. Boulos M, Astiz ME, Barua RS, Osman M. Impaired mitochondrial function induced by serum from septic shockpatients is attenuated by inhibition of nitric oxide synthase and poly(ADPribose) synthase. Crit Care Med. 2003;31:353-8.

49. Brealey D, Brand M, Hargreaves I, Heales S, Land J, Smolenski R, et al. Association between mitochondrial dysfunction and severity and outcome of septic shock. Lancet. 2002;360:219-23.

50. Chen Y, Wang Y, Chen J, Chen X, Cao W, Chen S, et al. Roles of transcriptional corepressor RIP140 and coactivator PGC-1alpha in energy state of chronically infarcted rat hearts and mitochondrial function of cardiomyocytes. Mol Cell Endocrinol. 2012;362:11-8.

51. Finck BN, Kelly DP. Peroxisome proliferator-activated receptor gamma coactivator-1 (PGC-1) regulatory cascade in cardiac physiology and disease. Circulation. 2007;115:2540-8.

52. Grégoire M, Tadié JM, Uhel F, Gacouin A, Piau C, Bone N, et al. Frontline science: HMGB1 induces neutrophil dysfunction in experimental sepsisand in patients who survive septic shock. J Leukoc Biol. 2017;101(6):1281-7.

53. Liu Z, Bone N, Jiang S, Park DW, Tadie JM, Deshane J, et al. AMP-activated protein kinase and Glycogen Synthase Kinase $3 \beta$ modulate the severity of sepsis-induced lung injury. Mol Med. 2015;21:937. https://doi.org/10.2119/molmed.2015.00198.

54. Stoll BJ, Shame AL. Infections of the neonatal infant. In: Kliegman R, Stanton B, St Geme J, Schor N, editors. Nelson textbook of pediatrics. 20th ed. Philadelphia: Elsevier; 2015. p. 909-25.

55. WHO. WHO guidelines on drawing blood: best practices in phlebotomy. 2010. http://apps. who.int/iris/bitstream/10665/44294/1/9789241599221_eng.pdf. Accessed 18 Apr 2017.

56. Malcolmson C, Ng K, Hughes S, Kissoon N, Schina J, Tilley PA, et al. Impact of matrixassisted laser desorption and ionization time-of-flight and antimicrobial stewardship intervention on treatment of bloodstream infections in hospitalized children. J Pediatric Infect Dis Soc. 2017;6(2):178-86.

57. Ruangkit C, Satpute A, Vogt BA, Hoyen C, Viswanathan S. Incidence and risk factors of urinary tract infection in very low birth weight infants. J Neonatal Perinatal Med. 2016;9:83-90.

58. Benitz WE. Adjunct laboratory tests in the diagnosis of early-onset neonatal sepsis. Clin Perinatol. 2010;37:421-38.

59. Newman TB, Draper D, Puopolo KM, Wi S, Escobar GJ. Combining immature and total neutrophil counts to predict early onset sepsis in term and late preterm newborns: use of the I/T2. Pediatr Infect Dis J. 2014;33:798-802.

60. Pugni L, Pietrasanta C, Milani S, Vener C, Ronchi A, Falbo M, et al. Presepsin (soluble CD14 subtype): reference ranges of a new sepsis marker in term and preterm neonates. PLoS One. 2015;10(12):e014602070.

61. Mussap M, Puxeddu E, Puddu M, Ottonello G, Coghe F, Comite P, et al. Soluble CD14 subtype (sCD14-ST) presepsin in premature and full term critically ill newborns with sepsis and SIRS. Clin Chim Acta. 2015;451:65-70.

62. Hofer N, Zacharias E, Muller W, Resch B. An update on the use of C-reactive protein in earlyonset neonatal sepsis: current insights and new tasks. Neonatology. 2012;102:25-36.

63. Bhandari V. Effective biomarkers for diagnosis of neonatal sepsis. J Pediatric Infect Dis Soc. 2014;3:234-45. 
64. Rotshenker-Olshinka K, Shinwell ES, Juster-Reicher A, Rosin I, Flidel-Rimon O. Comparison of hematologic indices and markers of infection in umbilical cord and neonatal blood. J Matern Fetal Neonatal Med. 2014;27:625-8.

65. Beeram MR, Loughran C, Cipriani C, Govande V. Utilization of umbilical cord blood for the evaluation of group B streptococcal sepsis screening. Clin Pediatr (Phila). 2012;51:447-53.

66. Meena J, Charles MV, Ali A, Ramakrishnan S, Gosh S, Seetha KS. Utility of cord blood culture in early onset neonatal sepsis. Australas Med J. 2015;8:263-7.

67. Su H, Chang SS, Han CM, et al. Inflammatory markers in cord blood or maternal serum for early detection of neonatal sepsis-a systemic review and meta-analysis. J Perinatol. 2014;34:268-74.

68. Howman RA, Charles AK, Jacques A, Doherty DA, Simmer K, Strunk T, et al. Inflammatory and haematological markers in the maternal, umbilical cord and infant circulation in histological chorioamnionitis. PLoS One. 2012;7:e51836.

69. Buhimschi CS, Bhandari V, Han YW, Dulay AT, Baumbusch MA, Madri JA, et al. Using proteomics in perinatal and neonatal sepsis: hopes and challenges for the future. Curr Opin Infect Dis. 2009;22:235-43.

70. Buhimschi CS, Bhandari V, Hamar BD, Bahtiyar MO, Zhao G, Sfakianaki AK, et al. Proteomic profiling of the amniotic fluid to detect inflammation, infection, and neonatal sepsis. PLoS Med. 2007;4:e18.

71. Ng PC, Ang IL, Chiu RW, Li K, Lam HS, Wong RP, Chui KM, et al. Host-response biomarkers for diagnosis of late-onset septicemia and necrotizing enterocolitis in preterm infants. J Clin Invest. 2010;120:2989-3000.

72. Dessì A, Corsello G, Stronati M, Gazzolo D, Caboni P, Carboni R, et al. New diagnostic possibilities in systemic neonatal infections: metabolomics. Early Hum Dev. 2014;90(Suppl 1):S19-21.

73. Fanos V, Caboni P, Corsello G, Stronati M, Gazzolo D. Urinary 1 H-NMR and GC-MS metabolomics predicts early and late onset neonatal sepsis. Early Hum Dev. 2014;90:S78-83.

74. Mckiernan CA, Lieberman SA. Circulatory shock in children: an overview. Pediatr Rev. 2005;26(12):451-60.

75. Caresta E, Papoff P, Valentini SB, Mancuso M, Cicchetti R. What's new in the treatment of neonatal shock. J Matern Fetal Neonatal Med. 2011;24(sup1):17-9.

76. Sivanandan S, Soraisham AS, Swarnam K. Choice and duration of antimicrobial therapy for neonatal sepsis and meningitis. Int J Pediatr. 2011;2011:712150.

77. Garciaprats JA, Cooper TR, Schneider VF, Stager CE, Hansen TN. Rapid detection of microorganisms in blood cultures of newborn infants utilizing an automated blood culture system. Pediatrics. 2000;105(3 Pt 1):523-7.

78. Saini SS, Dutta S, Ray P, Narang A. Short course versus 7-day course of intravenous antibiotics for probable neonatal septicemia: a pilot, open-label, randomized controlled trial. Indian Pediatr. 2011;48:19-24.

79. Ehl S, Gering B, Bartmann P, Högel J, Pohlandt F. C-reactive protein is a useful marker for guiding duration of antibiotic therapy in suspected neonatal bacterial infection. Pediatrics. 1997;99:216-21.

80. Al-Zwaini EJ. C-reactive protein: a useful marker for guiding duration of antibiotic therapy in suspected neonatal septicaemia? East Mediterr Health J. 2009;15:269-75.

81. Stocker M, Fontana M, El Helou S, et al. Use of procalcitonin-guided decision-making to shorten antibiotic therapy in suspected neonatal early-onset sepsis: prospective randomized intervention trial. Neonatology. 2010;97:165-74.

82. Murphy K, Weiner J. Use of leukocyte counts in evaluation of early-onset neonatal sepsis. Pediatr Infect Dis J. 2012;31:16-9.

83. Molyneux E, Nizami SQ, Saha S, Huu KT, Azam M, Bhutta ZA, Zaki R, Weber MW, Qazi SA. 5 versus 10 days of treatmentwith ceftriaxone for bacterial meningitis in children: a doubleblind randomised equivalence study. Lancet. 2011;377(9780):1837-45.

84. Greenwood C, Morrow AL, Lagomarcino AJ, Altaye M, Taft DH, Yu Z, et al. Early empiric antibiotic use in preterm infants is associated with lower bacterial diversity and higher relative abundance of Enterobacter. J Pediatr. 2014;165:23-9. 
85. Vincent JL, Ramesh MK, Ernest D, LaRosa SP, Pachl J, Aikawa N, et al. A randomized, double-blind, placebo-controlled, Phase $2 \mathrm{~b}$ study to evaluate the safety and efficacy of recombinant human soluble thrombomodulin, ART-123, in patients with sepsis and suspected disseminated intravascular coagulation. Crit Care Med. 2013;41:2069-79.

86. Levin M, Quint PA, Goldstein B, Barton P, Bradley JS, Shemie SD, et al. Recombinant bactericidal/permeability-increasing protein (rBPI 21) as adjunctive treatment for children with severe meningococcal sepsis: a randomised trial. Lancet. 2000;356:961-7.

87. López A, Lorente JA, Steingrub J, Bakker J, McLuckie A, Willatts S, et al. Multiple-center, randomized, placebo-controlled, double-blind study of the nitric oxide synthase inhibitor 546C88: effect on survival inpatients with septic shock. Crit Care Med. 2004;32:21-30.

88. Carr R, Modi N, Doré CJ. G-CSF and GM-CSF for treating or preventing neonatal infections. Cochrane Libr. 2003;3(3):CD003066.

89. Kreymann KG, de Heer G, Nierhaus A, Kluge S. Use of polyclonal immunoglobulins as adjunctive therapy for sepsis or septic shock. Crit Care Med. 2007;35:2677-85.

90. Akdag A, Dilmen U, Haque K, Dilli D, Erdeve O, Goekmen T. Role of pentoxifylline and/ or IgM-enriched intravenous immunoglobulin in the management of neonatal sepsis. Am J Perinatol. 2014;31(10):905-12.

91. The INIS Collaborative Group. Treatment of neonatal sepsis with intravenous immune globulin. N Engl J Med. 2011;365:1201-11.

92. Zhou F, Peng Z, Murugan R, Kellum JA. Blood purification and mortality in sepsis: a metaanalysis of randomized trials. Crit Care Med. 2013;41:2209-20.

93. Kalil AC, Florescu MC. Blood purification: can we purify our patients from sepsis. Crit Care Med. 2013;41:2244-5.

94. Nguyen TC, Kiss JE, Goldman JR, Carcillo JA. The role of plasmapheresis in critical illness. Crit Care Clin. 2012;28:453-68.

95. Macrae D, Grieve R, Allen E, Sadique Z, Morris K, Pappachan J, et al. CHiP investigators: a rando-mized trial of hyperglycemic control in pediatric intensive care. N Engl J Med. 2014;370:107-18.

96. Choong K, Bohn D, Fraser DD, Gaboury I, Hutchison JS, Joffe AR, Canadian Critical Care Trials Group, et al. Vasopressin in pediatric vasodilatory shock: a multicenter randomized controlled trial. Am J Respir Crit Care Med. 2009;180:632-9.

97. de Oliveira CF, de Oliveira DS, Gottschald AF, Moura JD, Costa GA, Ventura AC, et al. ACCM/PALS haemodynamic support guidelines for paediatric septic shock: an outcomes comparison with and without monitoring central venous oxygen saturation. Intensive Care Med. 2008;34:1065-75.

98. Chapman CE, Stainsby D, Jones H, Love E, Massey E, Win N, Serious Hazards of Transfusion Steering Group, et al. Ten years of hemovigilance reports of transfusion-related acute lung injury in the United Kingdom and the impact of preferential use of male donor plasma. Transfusion. 2009;49:440-52.

99. Karam O, Tucci M, Ducruet T, Hume H, Lacroix J, Gauvin F, Canadian Critical Care Trials Group, The PALISI Network. Red blood cell transfusion thresholds in pediatric septic patients. Pediatr Crit Care Med. 2011;12:512-8. 